\title{
Ultraviolet Photodissociation of Carboxylate- Derivatized Peptides in a Quadrupole Ion Trap
}

\author{
Byoung Joon Ko, ${ }^{1}$ Jennifer S. Brodbelt ${ }^{2}$ \\ ${ }^{1}$ Department of Chemical Engineering, University of Texas at Austin, 1 University Station A5300, Austin, TX, USA \\ ${ }^{2}$ Department of Chemistry \& Biochemistry, The University of Texas at Austin, 1 University Station A5300, Austin, TX \\ 78712, USA
}

\begin{abstract}
The fragmentation patterns obtained by ultraviolet photodissociation (UVPD) and collisioninduced dissociation (CID) in a quadrupole ion trap mass spectrometer were compared for peptides modified at their C-termini and at acidic amino acids. Attachment of Alexa Fluor 350 or 7-amino-4-methyl-coumarin chromophores at the C-terminal and acidic residues enhances the UV absorptivity of the peptides and all fragment ions that retain the chromophore, such as the $y$ ions that contain the chromophore-modified C-terminus. Whereas CID results in the formation of the typical array of mainly y-type and a/b-type fragment ions, UVPD produces predominantly a/ b-type ions with greatly reduced abundances of y ions. Immonium ions, mostly ones from aromatic or basic amino acids, are also observed in the low $\mathrm{m} / \mathrm{z}$ range upon UVPD. UVPD of peptides containing two chromophore moieties (with one at the C-terminus and another at an acidic residue) results in even more efficient photodissociation at the expense of the annihilation of almost all diagnostic $b$ and $y$ ions containing the chromophore.
\end{abstract}

Key words: Photodissociation, Peptide, Sequencing, Ion activation

\section{Introduction}

$\mathrm{T}$ he activation of ions in the gas phase has undergone a renaissance with the development of new electron-based [1-5] and photon-based [6-13] methods for energizing molecules, leading to fragmentation patterns that are often complementary to those obtained by more conventional collision-induced dissociation (CID) [14]. These methods have shown tremendous success in the structural characterization of numerous classes of molecules, especially for the determination of sequences and modifications of biopolymers like proteins, nucleic acids and carbohydrates [12, 13, $15,16]$. For the determination of peptide sequences, CID generally promotes highly efficient, low-energy fragmenta-

Electronic supplementary material The online version of this article (doi:10.1007/s13361-010-0016-5) contains supplementary material, which is available to authorized users.

Correspondence to: Jennifer Brodbelt; e-mail: jbrodbelt@mail.utexas.edu tion pathways that yield $\mathrm{y}$ and $\mathrm{a} / \mathrm{b}$ ions through cleavages of amide bonds. The more recent electron-based methods, including electron capture dissociation $[1,2]$ (ECD) in FTICR instruments and electron transfer dissociation (ETD) [3-5] in quadrupole ion traps, lead to nonergodic processes that produce $\mathrm{c}$ and $\mathrm{z}$ ions and typically allow the retention of post-translational modifications.

Both infrared multiphoton dissociation (IRMPD) and ultraviolet photodissociation (UVPD) have also shown considerable success for peptide sequencing [12, 13]. Successful photodissociation of peptides has been demonstrated using a $\mathrm{CO}_{2}$ laser $(10.6 \mu \mathrm{m}, 0.1 \mathrm{eV}$ per photon) [8, 17-19], an $\mathrm{F}_{2}$ excimer laser (157 nm, $7.9 \mathrm{eV}$ per photon) [20-22], an ArF excimer (193 nm, $6.4 \mathrm{eV}$ per photon) [23, 24], a Nd:YAG laser $(266 \mathrm{~nm}, 4.7 \mathrm{eV}$ per photon or $355 \mathrm{~nm}$, $3.5 \mathrm{eV}$ per photon) [25-32], and a femtosecond titanium sapphire laser $(800 \mathrm{~nm}, 1.5 \mathrm{eV}$ per photon) [33]. For example, Reilly et al. reported the UVPD of peptides that involved $157 \mathrm{~nm}$ photodissociation with an $\mathrm{F}_{2}$ excimer laser [20]. The dominant fragment ions were $\mathrm{x}-, \mathrm{v}-$, and w-type or

Received: 30 July 2010

Revised: 22 September 2010

Accepted: 13 October 2010

Published online: 21 January 2011 
a- and d-type ions, as well as immonium ions, depending on the location of the arginine residue at the $\mathrm{C}$ - or N-terminus, and this vast array of fragment ions was far greater than the typical b- and y-type ions observed upon CID. Kim et al. compared UVPD at $266 \mathrm{~nm}$ and $193 \mathrm{~nm}$ for a series of Argterminated peptides, finding an array of a, $\mathrm{d}, \mathrm{x}$, and $\mathrm{w}$ ions at both wavelengths, in addition to $\mathrm{v}$ ions at $193 \mathrm{~nm}$ and both $\mathrm{b}$ and y ions at $266 \mathrm{~nm}$ [23]. Dugourd et al. reported the observation of $\mathrm{H}$-atom losses and side-chain cleavages for peptides after UV excitation at 220 or $280 \mathrm{~nm}$ [32]. Zubarev et al. demonstrated that intra- and inter-disulfide bonds in peptides were selectively cleaved upon irradiation with $157 \mathrm{~nm}$ photons [22]. Joly et al. reported the cleavage of the $\mathrm{C}-\mathrm{C}$ bonds of tyrosine residues, producing radical ions which yielded complementary information upon subsequent CID [34]. The Julian group generated a radical site on the side chain of a tyrosine residue with iodine labeling and UVPD at $266 \mathrm{~nm}$ [28]. Subsequent CID of this radical product led to cleavage in proximity to the tyrosine residue. Julian et al. also explored UV photodissociation of peptides derivatized at serine and threonine phosphorylation sites via the attachment of thio-naphthyl chromophores that proved susceptible to photocleavage [26]. More recently, UVPD using a femtosecond laser $(800 \mathrm{~nm}, 300 \mu \mathrm{J} /$ pulse $)$ was demonstrated by Reid et al., resulting in the production of all major types of peptide fragment ions (a, b, c, w, x, y, z) [33]. In contrast, IRMPD of multicharged peptides in a quadrupole ion trap results in fragmentation patterns that are similar to those obtained upon CID, albeit with a greater array of fragment ions from the secondary dissociation of primary product ions that extend to the lower $\mathrm{m} / \mathrm{z}$ range and allow more confident sequencing of the termini of peptides [17, $19,35,36]$.

The success of photodissociation depends on the presence of suitable chromophores in the ions of interest, and this criterion poses both a challenge and an extra element of selective tunability. If ions do not possess appropriate chromophores, then their lack of photoabsorptivity will prevent energization and dissociation. On the other hand, attachment of chromophores offers the opportunity to convert nonabsorbing molecules into absorbing ones and thus change the response to photoirradiation. The addition of chromophores typically entails the derivatization of molecules by reactions undertaken in solution prior to ionization and mass spectrometric analysis. In one of the founding studies, Tecklenburg et al. derivatized amino acids and small peptides with dinitrophenyl and produced photofragments upon irradiation with $350 \mathrm{~nm}$ photons [37].

There are a number of derivatization strategies employed in conjunction with subsequent mass spectrometric analysis with the purpose of changing the ionization efficiencies of molecules (e.g., by adding ionizable sites or fixed charges) [38], modifying the hydrophobicities [39, 40], changing the fragmentation patterns of ions [18, 31,41], adding isotopic labels to facilitate quantitation, as in the popular iTRAQ methods [42, 43], or derivatizing molecules with dyes to probe conformational dynamics [44]. With respect to enhancing photodissociation efficiencies or exploiting the selectivity of photoabsorption through the derivatization of peptides, we have reported several recent strategies $[18,31$, 36, 45, 46]. For example, IRMPD of N-terminal sulfonated peptides enhanced the de novo sequencing of peptides by producing a complete series of $\mathrm{y}$ ions down to the $\mathrm{y}_{1}$ fragment [18]. The IRMPD efficiencies and sequence coverage of peptides were further increased by using a novel N-terminal phosphorylated phenylisothiocyanate reagent due to the high absorptivity of the phosphonite group at $10.6 \mu \mathrm{m}$ [45]. We also developed two chromogenic crosslinking agents that allowed facile differentiation of conjugated peptides from unmodified ones based on selective photoabsorptivity and dissociation upon IRMPD (using a phosphate chromophore) [36] or UVPD (using a bis-aryl hydrazone chromophore) [46].

We have been interested in evaluating the impact of the location of the chromophore on the photodissociation of peptides, so we have begun to explore the derivatization of peptides at their $\mathrm{N}$-termini versus their $\mathrm{C}$-termini. In a previous study, UVPD $(355 \mathrm{~nm})$ of peptides derivatized at their N-termini resulted in fragmentation patterns dominated by a simple series of $y$ ions due to the annihilation of the complementary chromophore-containing $b$ ions upon UV irradiation [31]. In the present study, peptides are derivatized at their C-termini by the same types of chromophores used in the prior study (Alexa Fluor 350 or 7-amino-4methylcoumarin, see Figure 1), and then characterized by UVPD. Our C-termini derivatization method is based on one recently reported by $\mathrm{Xu}$ et al. [39]. Carboxylic acid groups of peptides, including the C-terminus, glutamic acid, and aspartic acid, are readily modified via the incorporation of an amine functional group through hydrazide/EDC coupling. Based on this method, we explore the application of UVPD at $355 \mathrm{~nm}$ in a quadrupole ion trap for C-terminus derivatized peptides. Upon UVPD, the hydrazide-modified peptides produce fewer $\mathrm{y}$-type ions and more $\mathrm{a} / \mathrm{b}$-type ions. Also, in contrast to CID, numerous immonium ions are detected, especially ones associated with aromatic and basic residues.

\section{Experimental}

\section{Reagents}

7-Amino-4-methyl-coumarin-3-acetic acid hydrazide (AMCA) was purchased from Pierce (Rockford, IL, USA), and Alexa Fluor 350 hydrazide (AF350) was purchased from Invitrogen (Carlsbad, CA, USA). All peptides were purchased from Bachem (King of Prussia, PA, USA) except AAKAK, which was synthesized by Bio Basic (Ontario, Canada). 1-Ethyl-3-(3-dimethylaminopropyl) carbodiimide (EDC) was purchased from Pierce (Rockford, IL, USA). 1Hydroxy-7-azabenzotriazole (HOAt) was purchased from 
<smiles>Cc1c(CC(=O)NN)c(=O)oc2cc(N)c(S(=O)(=O)O)cc12</smiles>

Alexa Fluor 350 hydrazide (AF350) $\lambda_{\max } 346 \mathrm{~nm}=19,000 \mathrm{M}^{-1} \mathrm{~cm}^{-1}$ [+309 ]<smiles>Cc1c(CC(=O)NN)c(=O)oc2cc(N)ccc12</smiles>

7-amino-4-methyl-coumarin3-acetic acid hydrazide (AMCA) $\lambda_{\max } 353 \mathrm{~nm}=19,000 \mathrm{M}^{-1} \mathrm{~cm}^{-1}$ [+229]

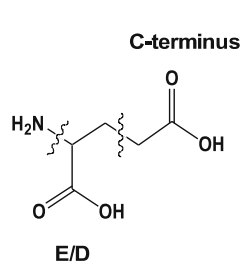<smiles>Cc1ccc2c(C)c(CC(O)NN)c(C)cc2c1</smiles><smiles>Cc1c(CC(=O)NNC(=O)CCC(N)C(=O)NNC(=O)Cc2c(C)c3ccc(N)cc3oc2=O)c(=O)oc2cc(N)ccc12</smiles>

Figure 1. Structures of the derivatization agents used for carboxylate modification. The solution-phase molar absorptivity at $\lambda_{\max }$ is given, as well as the nominal mass addition to peptides in square brackets. The scheme shows the typical derivatization pathway

AappTec (Louisville, KY, USA). All solvents were ACS spectroscopic grade from Fisher Scientific (Pittsburgh, PA, USA) and were used without any further purification.

\section{Peptide Derivatization}

The derivatization of carboxylic acids in peptides was performed based on a recent report [39]. In brief, $6 \mu \mathrm{L}$ of a hydrazide reagent solution $(2 \mathrm{mg} / \mathrm{mL})$ in DMF, $4 \mu \mathrm{L}$ of an EDC solution $(2 \mathrm{mg} / \mathrm{mL})$ in DMF, $3 \mu \mathrm{L}$ of an HOAt solution $(2 \mathrm{mg} / \mathrm{mL})$ in DMF, and $1 \mu \mathrm{L}$ of aqueous TFA $(0.1 \%)$ were added sequentially to an aqueous peptide solution $(0.1 \mathrm{mg} /$ $\mathrm{mL}, \sim 100 \mu \mathrm{M}, 50 \mu \mathrm{L}$ volume). After vortexing for several seconds, each derivatized peptide was dried via vacuum centrifugation in order to terminate the reaction. The dried peptides were desalted and the unreacted reagents were removed using a PepClean C18 spin column from Pierce Biotechnology, and then diluted with 50/50/1 methanol/ $\mathrm{H}_{2} \mathrm{O} /$ acetic acid (v/v) solution to $10 \mu \mathrm{M}$. The derivatization efficiencies were estimated to range from $\sim 20 \%$ to $60 \%$ based on the ion abundances of the derivatized peptides compared to the underivatized peptides (assuming similar ESI efficiencies).

\section{Mass Spectrometry}

All experiments were performed on a Thermo LCQ Deca XP (San Jose, CA, USA) mass spectrometer equipped with an electrospray source (ESI) and modified for photodissociation as described previously [31]. In a typical experiment, each peptide solution was diluted to a concentration of $10 \mu \mathrm{M}$ in 50/50/1 methanol/water/acetic acid for ESI-MS analysis. The solution was injected into the ESI source using a Harvard Apparatus PHD 2000 syringe pump (Holliston, MA, USA) at $5 \mu \mathrm{L} / \mathrm{min}$. Ion accumulation time was $20 \mathrm{~ms}$. For CID, the ion activation was performed at a $q$ value of 0.25 . All other instrumental parameters were optimized to increase the abundance of the precursor ions of interest prior to MS/MS analysis. The mass spectrometer was equipped with a Quanta-Ray GCR-11 Nd:YAG laser with a HG-2 harmonics generator from Spectra Physics (Mountain View, CA, USA) to generate the tripled harmonic photons at $355 \mathrm{~nm}$. The laser was operated at $10 \mathrm{~Hz}$ with full-energy pulses at $(\sim 60 \mathrm{~mJ} /$ pulse $)$, and the number of pulses were reported for each experiment.

\section{Results and Discussion}

A series of peptides were derivatized by attaching the AF350 or AMCA chromophores at their C-termini and at acidic residues (glutamic and aspartic acids), when present. Since peptides (even ones with aromatic residues) do not absorb strongly at $355 \mathrm{~nm}$, this means that the derivatization of peptides with chromophores that absorb at $355 \mathrm{~nm}$ creates a route to the selective photoactivation of only those molecules that are derivatized. The reactions are reasonably fast 
(typically requiring $1 \mathrm{~min}$ ) and efficient, resulting in good yields $(\sim 20 \%$ to $60 \%)$ of the derivatized peptides with minimal sample clean-up. An example of the type of derivatized peptide produced from the hydrazide coupling reaction is shown in Figure 1. In the present study, the CID and UVPD fragmentation patterns of the derivatized peptides are compared to the CID patterns of the nonderivatized peptides, with emphasis placed on the types and distribution of fragment ions produced upon UVPD versus CID.

\section{Comparison of UVPD and CID of Carboxylate- Derivatized Peptides}

The hydrazide reagents shown in Figure 1 react with carboxylate groups, including both the C-termini of peptides and aspartic acid and glutamic acid residues. To restrict the reaction solely to the C-termini for the first phase of the study, six peptides without any amino acids containing acidic side chains were selected. CID mass spectra of these six protonated peptides were collected as benchmark data, and an example is shown in Figure 2a for doubly charged ASHLGLAR. CID of simple peptides typically results in an array of $\mathrm{b}$ and $\mathrm{y}$ ions, often with some occasional a ions, and this is characteristic of the CID mass spectrum in Figure 2a. A variety of $b$ and $y$ ions are observed, as well as some minor secondary losses of water or ammonia from the $b$ and $y$ ions. Due to the loss of the storage of the lower $\mathrm{m} / \mathrm{z}$ range upon CID, immonium ions are not detected. Upon AMCA derivatization, the ASHLGLSR peptide gives a similar series of $\mathrm{b}$ and $\mathrm{y}$ ions upon CID, and the $\mathrm{y}$ ions retain the AMCA modification at the C-terminus (Figure 2b). UVPD of ASHLGLAR-AMCA results in predominantly $b$ ions with few y ions (Figure 2c), and the two surviving y ions, $\left(\mathrm{y}_{4}+\right.$ AMCA) and $\left(\mathrm{y}_{5}+\mathrm{AMCA}\right)$, are significantly reduced in abundance. The elimination of the $y$ ions from the UVPD spectrum is attributed to the rapid and efficient photodegradation of these ions upon exposure to multiple laser pulses. Since the AMCA chromophore is appended to the Cterminus of each $\mathrm{y}$ ion, these ions may undergo photoabsorption upon each sequential laser pulse, ultimately leading to their decomposition. The $\mathrm{b}$ ions possess no UV chromophores and thus remain as stable nonabsorbing ions in the ion trap. Another possibility is that protons migrate to the AMCA or AF350 moieties prior to or during activation, leading to sequestration of the protons, which results in the neutralization of sequence ions if the charged chromophore moiety detaches during ion dissociation. The lack of protonated AMCA and AF350 ions upon CID or UVPD and the prevalent survival of the chromophore-derivatized $y$ ions in the CID spectra offers evidence against this proton migration concept. Moreover, a series of immonium ions is observed in the low $\mathrm{m} / \mathrm{z}$ region in the UVPD spectrum of

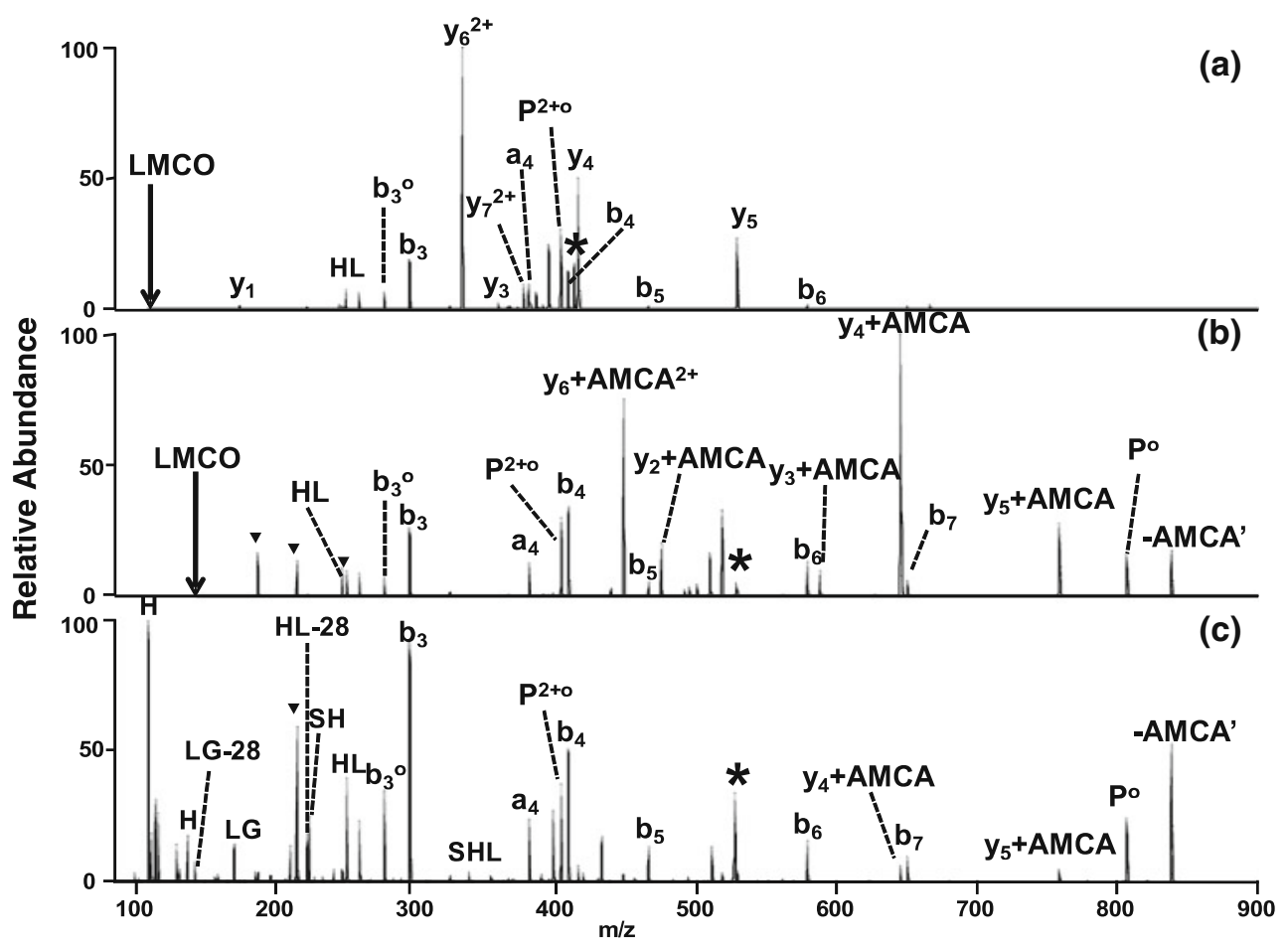

Figure 2. ESI-MS/MS spectra of the doubly protonated ASHLGLAR peptide obtained by (a) CID of the unmodified peptide, (b) CID of the AMCA-derivatized peptide, and (c) UVPD of the AMCA-derivatized peptide (15 pulses at $10 \mathrm{~Hz}$ ). An asterisk is used to signify the precursor; triangles represent fragments arising from the AMCA substituent; a superscript o represents the loss of $\mathrm{NH}_{3}$ or $\mathrm{H}_{2} \mathrm{O}$; $P$ represents a protonated ASHLGLAR; -AMCA' represents the loss of the AMCA chromophore with the retention of the hydrazine functionality by the peptide (see Figure 1) 
LQVQLSIR-AMCA, ones that were not observed upon CID due to the low mass cutoff. Immonium ions are frequently detected in hybrid quadrupole-time-of-flight mass spectrometers $[47,48]$, and have proven useful for the determination of amino acid compositional information and the assessment of post-translational modifications [48-50].

Three peptides each containing a single glutamic acid (E) or aspartic acid (D) residue were also subjected to the hydrazide derivatization procedure and analyzed by CID and UVPD. For these three peptides including DRVYIHPFHL, RKDVY, and FSWGAEGQR, the chromophore may attach at either the $\mathrm{C}$-terminus or E/D side chains, or at both the Cterminus and E/D side chains. Upon the derivatization procedure, both singly and doubly modified products were detected. The CID and UVPD results for doubly-charged, singly modified AMCA-DRVYIHPFHL are illustrated in Figure 3, along with the CID mass spectrum for the unmodified peptide. CID of the unmodified peptide predominantly results in an abundant series of $\mathrm{b}$ and $\mathrm{y}$ ions (Figure 3a). Similarly, the CID mass spectrum of the AMCA-modified peptide displays virtually the same series of $\mathrm{b}$ and $\mathrm{y}$ ions, most retaining the AMCA modification (Figure $3 b)$. The presence of both unmodified $b$ ions $\left(b_{5}, b_{6}\right.$, $\mathrm{b}_{8}$ and $\mathrm{b}_{9}$ ) in addition to the corresponding AMCA-modified $b_{n}$ ions indicates that the AMCA reaction occurred at either of the reactive sites: the C-terminus or the aspartic acid (the first amino acid in the sequence). The UVPD spectrum of AMCA-DRVYIHPFHL shows that the AMCA-modified $b$ and $y$ ions are no longer observed, indicating that they are annihilated upon UVPD (Figure 3c). In fact, the only abundant product ions observed upon UVPD are a series of immonium ions in the low $\mathrm{m} / \mathrm{z}$ range of the mass spectrum. The other two peptides, which contained amino acids with acidic side chains, RKDVY and FSWGAEGQR, showed similar results (i.e., low abundances of both $\mathrm{b}$ and $\mathrm{y}$ ions; see Electronic Supplementary Material Figure. 1 and Figure 4 and 5).

The CID and UVPD behavior of several doubly protonated, doubly derivatized peptides was also investigated. Examples of the resulting fragmentation patterns are shown in the Electronic Supplementary Material Figure 2 for RKDVY and FSWGAEGQR. In general, the UVPD spectra

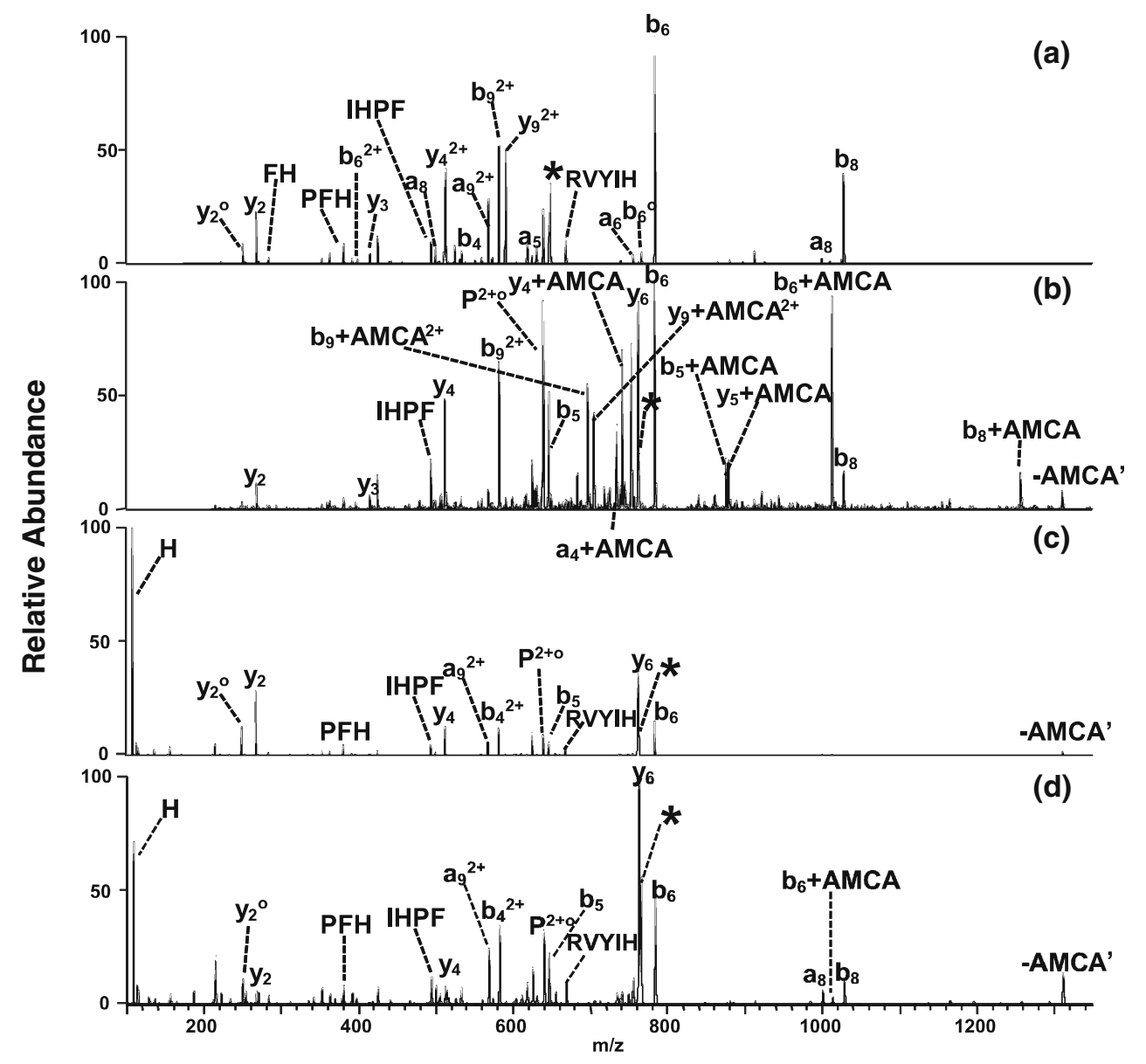

Figure 3. ESI-MS/MS spectra of the doubly protonated DRVYIHPFHL peptide by (a) CID of the unmodified peptide, (b) CID of the AMCA-derivatized peptide, (c), (d) UVPD of the AMCA-derivatized peptide (20 pulses at $10 \mathrm{~Hz}$ and 5 pulses at $10 \mathrm{~Hz}$, respectively). An asterisk is used to signify the precursor ion; a superscript o represents the loss of $\mathrm{NH}_{3}$ or $\mathrm{H}_{2} \mathrm{O}$; $P$ represents a protonated DRVYIHPFHL ion; -AMCA' represents the loss of the AMCA chromophore with the retention of the hydrazine functionality by the peptide 
(a)
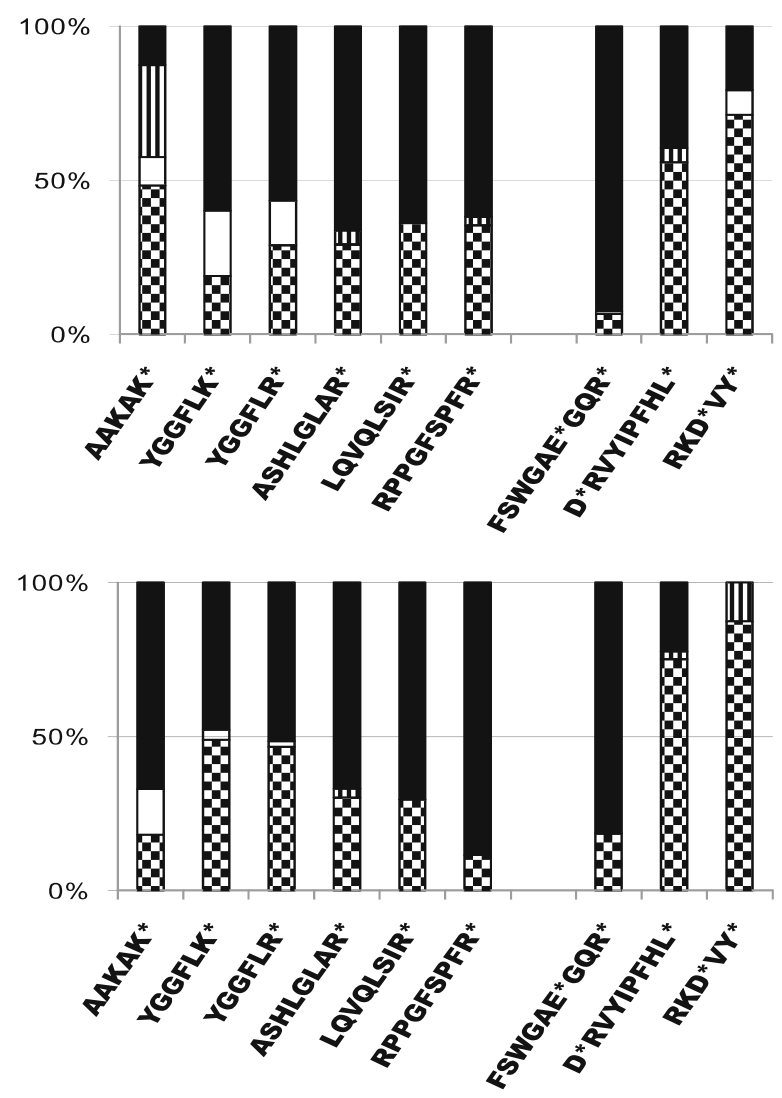

(b)

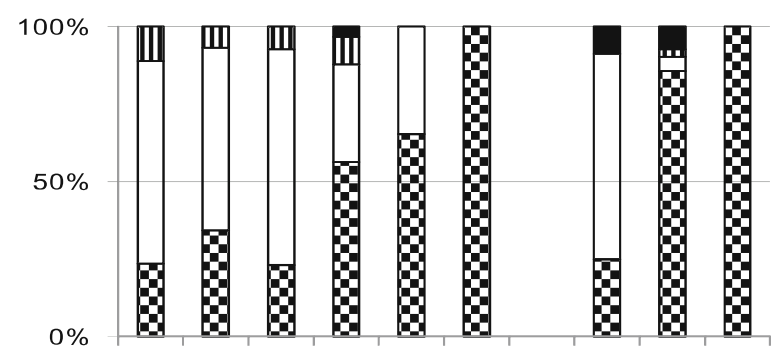

(c)

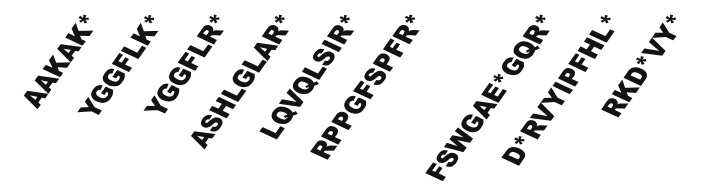

$\square$ y $\mathbf{m}$ Internal $\square$ Immonium $\mathbf{B}$ a/b

Figure 4. MS/MS bar graphs summarizing the distribution of various classes of fragment ion, including $y, a / b$, immonium ion, and internal ions formed upon the dissociation of doubly protonated AMCA-derivatized peptides. (a) CID of unmodified peptides, (b) CID of AMCA-derivatized peptides, and (c) UVPD of AMCA-derivatized peptides (20 pulses at $10 \mathrm{~Hz}$ ). The asterisks represent the expected possible derivatization sites. For (b) and (c), only singly modified peptides were analyzed. The three peptides containing amino acids with acidic side chains are grouped on the right-hand side

of the doubly protonated and doubly derivatized peptides show very low abundances of $b$ and $y$ ions, suggesting that virtually all of these ions are annihilated upon UVPD, and confirming that the presence of two UV chromophores leads

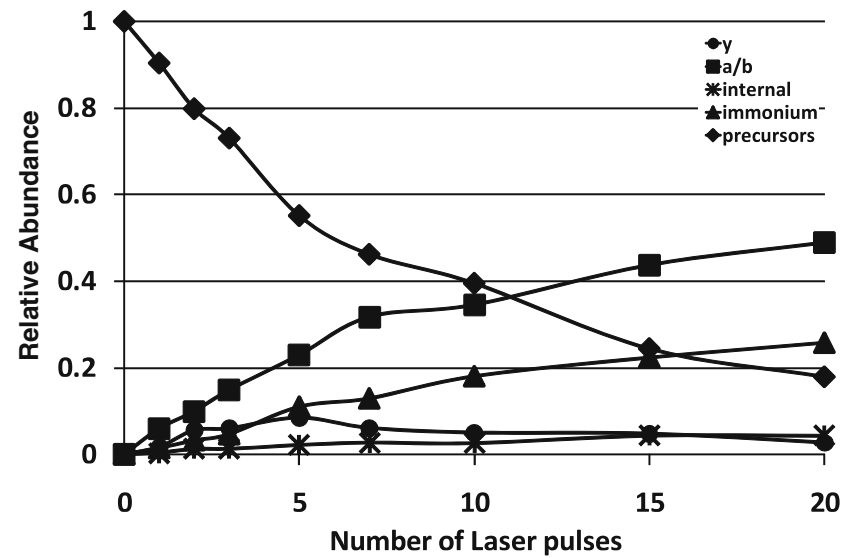

Figure 5. Percentage of ions (based on summed peak areas) versus the number of laser pulses (355 nm, $60 \mathrm{~mJ} /$ pulse at $10 \mathrm{~Hz}$ ) for doubly protonated LQVQLSIR-AMCA ions

to extensive absorption and photodegradation. Only immonium ions are especially abundant in the UVPD spectra, whereas both $\mathrm{b}$ and $\mathrm{y}$ ions are observed upon the CID of these doubly derivatized peptides.

A comparison of the CID and UVPD fragmentation patterns for an array of nine doubly protonated AMCAderivatized peptides is shown in bar-graph form in Figure 4, along with the comparative CID results for the unmodified peptides. The six peptides on the left-hand side all have lysine or arginine at the C-terminus, thus mimicking the types of sequences expected for tryptic peptides. Since these peptides do not contain any aspartic acid (D) or glutamic acid (E) residues, the hydrazide derivatization reactions are restricted to the $\mathrm{C}$-termini of these six peptides. The product ions were grouped into four categories, including all y ions, all internal ions, all immonium ions, and all a/b ions, and the abundances of those ions were summed to create the distributions that allow the easy visual comparisons shown in Figure 4. The distributions obtained upon the CID of the unmodified and AMCA-derivatized peptides generally show a predominance of $y$ and complementary $a / b$ ions, the two types of product ions typically expected upon the CID of protonated peptides (Figure $4 \mathrm{a}$ and $\mathrm{b}$ ). The abundances of $\mathrm{y}$ ions are significantly reduced in the UVPD distributions (Figure 4c), presumably due to the annihilation of ions containing the AMCA chromophore upon multiple laser pulses, as described above. The surviving non-chromophorecontaining $\mathrm{a} / \mathrm{b}$ ions thus make a correspondingly greater contribution to the product ion distributions. The immonium ions are also far more dominant in the UVPD spectra, and this is attributed to the alleviation of the low mass cutoff during the implementation of UVPD. Typically, the maximum $\mathrm{m} / \mathrm{z}$ value of an immonium ion is 171 (tryptophan), whereas immonium ions arising from other amino acids fall in the range $m / z 30-170$, a region excluded for traditional CID. As mentioned in the "Experimental" section, the $q$ value used for the UVPD experiments ranged from 0.1 to 0.15 , facilitating the trapping and subsequent detection of 
the lower $\mathrm{m} / \mathrm{z}$ immonium ions (see Electronic Supplementary Material Figure 3). Generally, the basic and aromatic amino acids produced the most abundant immonium ions upon UVPD of the C-terminal AMCA-derivatized peptides. It has been noted previously that the abundances of these ions generally correlate with the position of the amino acid in the sequence and the type of amino acid [47].

The three peptides on the right-hand side of Figure 4 contain aspartic acid (D) or glutamic acid (E) residues in the sequence, and thus the AMCA derivatization may occur at the C-terminus or at the acidic side chains. A small portion of y ions survive upon the UVPD of two of these peptides (FSWGAEGQR and DRVYIPF), more than observed for the other peptides. This result indicates that the derivatization reaction occurred at the side chain, not the $\mathrm{C}$-terminus site, for at least some fraction of those two peptides, thus allowing the survival of the y ions upon UVPD.

The peptides were also derivatized using a second Cterminal chromogenic hydrazide reagent, AF350, and the resulting AF350-derivatized peptides were analyzed along the same lines as the AMCA peptides. In most cases, similar trends were observed with respect to the types and distributions of fragment ions obtained upon CID or UVPD of the derivatized and unmodified peptides. For the same series of peptides, the comparative CID and UVPD results are summarized in Electronic Supplementary Material Figure 4. The extent of the annihilation of the y-type ions upon UVPD was diminished compared to that observed upon the UVPD of the AMCA-derivatized peptides, and the overall abundances of immonium ions were lower than those observed for the same AMCA-derivatized peptides. Moreover, the UVPD efficiencies were lower for the AF350 peptides compared to the AMCA peptides, a result consistent with our previous study of N-terminal AMCA- and AF350-derivatized peptides [31]. This behavior suggests that AF350 is a less effective chromophore at $355 \mathrm{~nm}$ or facilitates nondissociative energy release that decreases the photodissociation of the AF350-modified y ions.

\section{Impact of the Number of Laser Pulses on the Distribution of Fragment Ions}

The reduction in the abundances of $y$ ions and the concomitant increases in the relative abundances of $a / b$ and immonium ions upon UVPD is attributed to extensive secondary dissociation of fragments that retain the chromophore, as evidenced by our previous study of $\mathrm{N}$-terminal derivatized peptides [31]. This hypothesis was affirmed in the present study by examining the distribution of product ions upon UVPD as a function of the number of laser pulses (Figure 5). The trends in the relative abundances of $\mathrm{a} / \mathrm{b}, \mathrm{y}$, and immonium ions are shown graphically in Figure 5 for doubly protonated AMCA-derivatized LQVQLSIR after 120 pulses. The percentage of y-type ions peaked at 5 pulses and diminished thereafter, whereas the relative abundances of a/b-type ions and immonium ions increased with the number of laser pulses, as expected from the enhanced conversion of precursor ions to product ions and the secondary dissociation of y ions. This hypothesis was also confirmed by $\mathrm{MS}^{3}$ CID/UVPD experiments, with an example shown in Electronic Supplementary Material Figure 5. Two fragment ions, the $\mathrm{b}_{6}$ and $\mathrm{y}_{4}+$ AMCA ions, which formed upon the CID of doubly protonated AMCAderivatized ASHLGLAR, were isolated and subjected to UVPD. Upon UV irradiation, the $\mathrm{b}_{6}$ ion does not dissociate, whereas the $\mathrm{y}_{4}+$ AMCA ion undergoes extensive photodissociation. This result affirms the impact of the chromophore on the photodissociation efficiencies of the peptides and their products.

\section{Conclusion}

UVPD at $355 \mathrm{~nm}$ of carboxylate-derivatized peptides resulted in predominantly a/b-type ions compared to CID of the same peptides. Moreover, a variety of immonium ions were detected upon UVPD, affording compositional information not typically observed upon conventional CID. Both the AMCA and AF350-hydrazide derivatization methods yielded similar distributions of products, and those peptides containing two derivatized sites (such as those containing one acidic amino acid in addition to the $\mathrm{C}$-terminus) showed higher dissociation efficiencies, although they did not necessarily yield more diagnostic fragment ions. In contrast to the UVPD of N-terminally derivatized peptides, which enhanced the survival of $y$ ions, the UVPD of C-terminally derivatized peptides resulted in the preferential survival of a/ $\mathrm{b}$ ions and immonium ions, with the chromophore-modified $\mathrm{y}$ ions undergoing extensive secondary photodissociation that resulted in their elimination from the spectra.

\section{Acknowledgements}

Funding from the NSF (CHE-1012622) and the Welch Foundation (F1155) is gratefully acknowledged.

\section{References}

1. Zubarev, R.A.: Electron-capture dissociation tandem mass spectrometry. Curr. Opin. Biotechnol. 15, 12-16 (2004)

2. Zubarev, R.A., Kelleher, N.L., McLafferty, F.W.: Electron capture dissociation of multiply charged protein cations. A nonergodic process. J. Am. Chem. Soc. 120, 3265-3266 (1998)

3. Syka, J.E.P., Coon, J.J., Schroeder, M.J., Shabanowitz, J., Hunt, D.F.: Peptide and protein sequence analysis by electron transfer dissociation mass spectrometry. Proc. Natl. Acad. Sci. U. S. A. 101, 9528-9533 (2004)

4. Coon, J.J., Shabanowitz, J., Hunt, D.F., Syka, J.E.P.: Electron transfer dissociation of peptide anions. J. Am. Soc. Mass Spectrom. 16, 880-882 (2005)

5. Coon, J.J., Ueberheide, B., Syka, J.E.P., Dryhurst, D.D., Ausio, J., Shabanowitz, J., Hunt, D.F.: Protein identification using sequential ion/ ion reactions and tandem mass spectrometry. Proc. Natl. Acad. Sci. U. S. A. 102, 9463-9468 (2005)

6. Little, D.P., Speir, J.P., Senko, M.W., Oconnor, P.B., McLafferty, F.W.: Infrared multiphoton dissociation of large multiply-charged ions for biomolecule sequencing. Anal. Chem. 66, 2809-2815 (1994)

7. Crowe, M.C., Brodbelt, J.S.: Infrared multiphoton dissociation (IRMPD) and collisionally activated dissociation of peptides in a 
quadrupole ion trap with selective IRMPD of phosphopeptides. J. Am. Soc. Mass Spectrom. 15, 1581-1592 (2004)

8. Payne, A.H., Glish, G.L.: Thermally assisted infrared multiphoton photodissociation in a quadrupole ion trap. Anal. Chem. 73, 3542-3548 (2001)

9. Choi, K.M., Yoon, S.H., Sun, M.L., Oh, J.Y., Moon, J.H., Kim, M.S.: Characteristics of photodissociation at $193 \mathrm{~nm}$ of singly protonated peptides generated by Matrix-Assisted Laser Desorption Ionization (MALDI). J. Am. Soc. Mass Spectrom. 17, 1643-1653 (2006)

10. Thompson, M.S., Cui, W.D., Reilly, J.P.: Fragmentation of singly charged peptide ions by photodissociation at Lambda $=157 \mathrm{~nm}$. Angew. Chem. Int. Ed. 43, 4791-4794 (2004)

11. Oh, J.Y., Moon, J.H., Kim, M.S.: Sequence- and site-specific photodissocniation at $266 \mathrm{~nm}$ of protonated synthetic polypeptides containing a tryptophanyl residue. Rapid Commun. Mass Spectrom. 18, 2706-2712 (2004)

12. Brodbelt, J.S., Wilson, J.J.: Infrared multiphoton dissociation in quadrupole ion traps. Mass Spectrom. Rev. 28, 390-424 (2009)

13. Reilly, J.P.: Ultraviolet photoframentation of biomolecular ions. Mass Spectrom. Rev. 28, 425-447 (2009)

14. Laskin, J., Futrell, J.H.: Collisional activation of peptide ions in FT-ICR mass spectrometry. Mass Spectrom. Rev. 22, 158-181 (2003)

15. Coon, J.J.: Collisions or electrons? Protein sequence analysis in the $21 \mathrm{st}$ century. Anal. Chem. 81, 3208-3215 (2009)

16. Ly, T., Julian, R.R.: Ultraviolet photodissociation: developments towards applications for mass-spectrometry-based proteomics. Angew. Chem. Int. Ed. 48, 7130-7137 (2009)

17. Crowe, M.C., Brodbelt, J.S.: Differentiation of phosphorylated and unphosphorylated peptides by high-performance liquid chromatography-electrospray ionization-infrared multiphoton dissociation in a quadrupole ion trap. Anal. Chem. 77, 5726-5734 (2005)

18. Wilson, J.J., Brodbelt, J.S.: Infrared multiphoton dissociation for enhanced de novo sequence interpretation of $\mathrm{N}$-terminal sulfonated peptides in a quadrupole ion trap. Anal. Chem. 78, 6855-6862 (2006)

19. Madsen, J.A., Brodbelt, J.S.: Comparison of infrared multiphoton dissociation and collision-induced dissociation of supercharged peptides in ion traps. J. Am. Soc. Mass Spectrom. 20, 349-358 (2009)

20. Kim, T.Y., Thompson, M.S., Reilly, J.P.: Peptide photodissociation at $157 \mathrm{~nm}$ in a linear ion trap mass spectrometer. Rapid Commun. Mass Spectrom. 19, 1657-1665 (2005)

21. Zhang, L.Y., Reilly, J.P.: Peptide photodissociation with $157 \mathrm{~nm}$ light in a commercial tandem time-of-flight mass spectrometer. Anal. Chem. 81, 7829-7838 (2009)

22. Fung, Y.M.E., Kjeldsen, F., Silivra, O.A., Chan, T.W.D., Zubarev, R.A.: Facile disulfide bond cleavage in gaseous peptide and protein cations by ultraviolet photodissociation at $157 \mathrm{~nm}$. Angew. Chem. Int. Ed. 44, 6399-6403 (2005)

23. Moon, J.H., Yoon, S.H., Kim, M.S.: Photodissociation of singly protonated peptides at $193 \mathrm{~nm}$ investigated with tandem time-of-flight mass spectrometry. Rapid Commun. Mass Spectrom. 19, 3248-3252 (2005)

24. Moon, J.H., Shin, Y.S., Cha, H.J., Kim, M.S.: Photo dissociation at $193 \mathrm{~nm}$ of some singly protonated peptides and proteins with $\mathrm{m} / \mathrm{z}$ 2,000-9000 using a tandem time-of-flight mass spectrometer equipped with a second source for delayed extraction/post-acceleration of product ions. Rapid Commun. Mass Spectrom. 21, 359-368 (2007)

25. Oh, J.Y., Moon, J.H., Lee, Y.H., Hyung, S.W., Lee, S.W., Kim, M.S.: Photodissociation tandem mass spectrometry at $266 \mathrm{~nm}$ of an aliphatic peptide derivatized with phenyl isothiocyanate and 4-sulfophentyl isothiocyanate. Rapid Commun. Mass Spectrom. 19, 1283-1288 (2005)

26. Diedrich, J.K., Julian, R.R.: Site-specific radical directed dissociation of peptides at phosphorylated residues. J. Am. Chem. Soc. 130, 12212-12213 (2008)

27. Park, S., Ahn, W.K., Lee, S., Han, S.Y., Rhee, B.K., Oh, H.B.: Ultraviolet photodissociation at $266 \mathrm{~nm}$ of phosphorylated peptide cations. Rapid Commun. Mass Spectrom. 23, 3609-3620 (2009)

28. Ly, T., Julian, R.R.: Residue-specific radical-directed dissociation of whole proteins in the gas phase. J. Am. Chem. Soc. 130, 351-358 (2008)

29. Wilson, J.J., Kirkovits, G.J., Sessler, J.L., Brodbelt, J.S.: Photodissociation of non-covalent peptide-crown ether complexes. J. Am. Soc. Mass Spectrom. 19, 257-260 (2008)

30. Yeh, G.K., Sun, Q.Y., Meneses, C., Julian, R.R.: Rapid peptide fragmentation without electrons, collisions, infrared radiation, or native chromophores. J. Am. Soc. Mass Spectrom. 20, 385-393 (2009)
31. Wilson, J.J., Brodbelt, J.S.: MS/MS simplification by $355 \mathrm{~nm}$ ultraviolet photodissociation of chromophore-derivatized peptides in a quadrupole ion trap. Anal. Chem. 79, 7883-7892 (2007)

32. Tabarin, T., Antoine, R., Broyer, M., Dugourd, P.: Specific photodissociation of peptides with multi-stage mass spectrometry. Rapid Commun. Mass Spectrom. 19, 2883-2892 (2005)

33. Kalcic, C.L., Gunaratne, T.C., Jonest, A.D., Dantus, M., Reid, G.E.: Femtosecond laser-induced ionization/dissociation of protonated peptides. J. Am. Chem. Soc. 131, 940-942 (2009)

34. Joly, L., Antoine, R., Broyer, M., Dugourd, P., Lemoine, J.: Specific UV photodissociation of tyrosyl-containing peptides in multistage mass spectrometry. J. Mass Spectrom. 42, 818-824 (2007)

35. Gardner, M.W., Smith, S.I., Ledvina, A.R., Madsen, J.A., Coon, J.J., Schwartz, J.C., Stafford, G.C., Brodbelt, J.S.: Infrared multiphoton dissociation of peptide cations in a dual pressure linear ion trap mass spectrometer. Anal. Chem. 81, 8109-8118 (2009)

36. Gardner, M.W., Vasicek, L.A., Shabbir, S., Anslyn, E.V., Brodbelt, J. S.: Chromogenic cross-linker for the characterization of protein structure by infrared multiphoton dissociation mass spectrometry. Anal. Chem. 80, 4807-4819 (2008)

37. Tecklenburg, R.E., Miller, M.N., Russell, D.H.: Laser ion beam photodissociation studies of model amino acids and peptides. J. Am. Chem. Soc. 111, 1161-1171 (1989)

38. Krusemark, C.J., Frey, B.L., Belshaw, P.J., Smith, L.M.: Modifying the charge state distribution of proteins in electrospray ionization mass spectrometry by chemical derivatization. J. Am. Soc. Mass Spectrom. 20, 1617-1625 (2009)

39. Xu, Y.W., Zhang, L.J., Lu, H.J., Yang, P.Y.: Mass spectrometry analysis of phosphopeptides after peptide carboxy group derivatization. Anal. Chem. 80, 8324-8328 (2008)

40. Zhang, L.J., Xu, Y.W., Lu, H.J., Yang, P.Y.: Carboxy group derivatization for enhanced electron-transfer dissociation mass spectrometric analysis of phosphopeptides. Proteomics 9, $4093-4097$ (2009)

41. Madsen, J.A., Brodbelt, J.S.: Simplifying fragmentation patterns of multiply charged peptides by N-terminal derivatization and electron transfer collision activated dissociation. Anal. Chem. 81, 3645-3653 (2009)

42. Ross, P.L., Huang, Y.L.N., Marchese, J.N., Williamson, B., Parker, K., Hattan, S., Khainovski, N., Pillai, S., Dey, S., Daniels, S., Purkayastha, S., Juhasz, P., Martin, S., Bartlet-Jones, M., He, F., Jacobson, A., Pappin, D.J.: Multiplexed protein quantitation in Saccharomyces cerevisiae using amine-reactive isobaric tagging reagents. Mol. Cell. Proteomics 3, 1154-1169 (2004)

43. DeSouza, L., Diehl, G., Rodrigues, M.J., Guo, J.Z., Romaschin, A.D., Colgan, T.J., Siu, K.W.M.: Search for cancer markers from endometrial tissues using differentially labeled tags iTRAQ and clCAT with multidimensional liquid chromatography and tandem mass spectrometry. J. Proteome Res. 4, 377-386 (2005)

44. Iavarone, A.T., Duft, D., Parks, J.H.: Shedding light on biomolecule conformational dynamics using fluorescence measurements of trapped ions. J. Phys. Chem. A 110, 12714-12727 (2006)

45. Vasicek, L.A., Wilson, J.J., Brodbelt, J.S.: Improved infrared multiphoton dissociation of peptides through N-terminal phosphonite derivatization. J. Am. Soc. Mass Spectrom. 20, 377-384 (2009)

46. Gardner, M.W., Brodbelt, J.S.: Ultraviolet photodissociation mass spectrometry of bis-aryl hydrazone conjugated peptides. Anal. Chem. 81, 4864-4872 (2009)

47. Hohmann, L.J., Eng, J.K., Gemmill, A., Klimek, J., Vitek, O., Reid, G. E., Martin, D.B.: Quantification of the compositional information provided by immonium ions on a quadrupole-time-of-flight mass spectrometer. Anal. Chem. 80, 5596-5606 (2008)

48. Shi, Y., Bairami, B., Morton, M., Yao, X.D.: Cyclophosphoramidate for ion as mass defect marker for efficient detection of protein serine phosphorylation. Anal. Chem. 80, 7614-7623 (2008)

49. Hung, C.W., Schlosser, A., Wei, J.H., Lehmann, W.D.: Collisioninduced reporter fragmentations for identification of covalently modified peptides. Anal. Bioanal. Chem. 389, 1003-1016 (2007)

50. Couttas, T.A., Raftery, M.J., Bernardini, G., Wilkins, M.R.: Immonium ion scanning for the discovery of post-translational modifications and its application to histones. J. Proteome Res. 7, 2632-2641 (2008) 